\title{
A Brief Survey of English Education of Tibetan Primary School in Ganzi County
}

\author{
Xiaojun $\mathrm{He}^{1} \&$ Xia $\mathrm{Lazo}^{2}$ \\ ${ }^{1}$ School of Foreign Languages, Leshan Normal University, China \\ ${ }^{2}$ Ganzi Middle School, Ganzi Prefecture, China \\ Correspondence: Xiaojun He, School of Foreign Languages, Leshan Normal University, Leshan, Sichuan, China. \\ Tel: 86-139-8137-6137. E-mail: 1stchxj@qq.com \\ Correspondence: Xia Lazo, Ganzi Middle School, Ganzi, Sichuan, China. Tel: 86-833-2277-878. E-mail: \\ 36759522@qq.com
}

Received: April 29, 2015 Accepted: August 8, 2015 Online Published: August 11, 2015

doi:10.5539/elt.v8n9p33 URL: http://dx.doi.org/10.5539/elt.v8n9p33

\begin{abstract}
The current social backgrounds have made English learning become an important part in every Chinese student's life. Tibetan students begin to study Tibetan, Chinese and English from primary school. However, in many Chinese ethnic-minorities areas like Tibetan areas, English education is facing many problems and challenges, especially the English education in primary schools. This thesis uses the field survey, questionnaires and interviews to study the general situation of English education in primary schools of Ganzi County. Then from the analyses of these surveys, this thesis aims to find the major problems and gives some creative solutions to them and let more people know the situation of English teaching in Tibetan primary schools and make them give more available suggestions.
\end{abstract}

Keywords: Tibetan areas, primary school, English education, Ganzi county

\section{Introduction}

\subsection{About Ganzi County}

Ganzi is one of the 18 counties of the Garzê Tibetan Autonomous Prefecture, in northwestern Sichuan province, China. The total area is $7,364 \mathrm{~km}^{2}$ and average elevation is $3,390 \mathrm{~m}$. The annual average temperature here is $5.6^{\circ} \mathrm{C}$. It has 22 towns and 219 villages. The total population of Ganzi is 58,000 , above $95 \%$ of whom are ethnic Tibetans.

Ganzi is a typical farming and animal husbandry county and it is the trade center of the northern Garzê Tibetan Autonomous Prefecture. With the development of the local economy, the living condition of the local Tibetans has been better than before. Many Han people from other areas of Sichuan province have come here to do business. Most of them open different kinds of grocery stores and restaurants. What's more, the local tourism has attracted many foreigners to Ganzi. Local Tibetan culture is now facing multiple cultural shocks.

As mother tongue, Tibetan is widely used in every Ganzi people's life from the daily chores to the documentation of the local government. So the language environment in Ganzi has been deeply influenced by Tibetan and the teaching of any other language should take the effect of Tibetan into consideration.

\subsection{The Primary Schools of Ganzi County}

This thesis is conducted to make an investigation to get more information about the current situation of English education in primary schools of Ganzi County and then through the analyses of the problems to find some available ways to solve these problems. In addition, this investigation can arouse more attention to the English education in Tibetan areas.

\subsection{Subjects}

149 students of No. 3 Complete Primary School are chosen from the $3^{\text {rd }}$ to $5^{\text {th }}$ grade in this investigation, among whom, 50 were selected from the $3^{\text {rd }}$ grade, 47 from $4^{\text {th }}$ grade while the rest from the $5^{\text {th }}$ grade. The 3 English teachers investigated are also from No.3 Complete Primary School. What's more, a staff named Luo Weidong in 
the Education Bureau of Ganzi County is interviewed to provide the further information about the number of the primary school students, the number of English teachers in primary schools and other information in detail.

\subsection{Instrument}

Questionnaire and interviews are mainly adopted in this research. Students chosen in No.3 Complete Primary School are required to do a questionnaire which aims to investigate their interest in English, problems in English, parents' English ability and their requirement to the English teachers. The English teachers are also invited to do a questionnaire to investigate their basic information and their ideas about the English education in Ganzi County. English teachers in No.3 Complete Primary School and a staff in Education Bureau of Ganzi County are also interviewed to get more information for this research.

\subsection{The Current Situation of the English Education in Primary Schools of Ganzi County}

\subsubsection{An Introduction to Primary Schools in Ganzi County}

Ganzi County has one kindergarten, 44 primary schools, including 3 private ones, and 1 middle school. There are totally 6,881 primary school students and 310 primary school teachers in the county. Complete Primary Schools from No.1 to No.3 are in the central town of Ganzi County, and most students study in No.2 and No.3 Complete Primary School. The three primary schools are all boarding schools and have teaching buildings, dormitories, playgrounds, dining halls and comprehensive buildings. No.2 Complete Primary School has been reconstructed and the new school was completed in August, 2013, which has better facilities than before and plans to extend the teaching scope. No.3 Complete Primary School has the most students in Ganzi. The study environment of primary schools in villages is not very good because of the lack of teachers, poor facilities, limited information and low motivation of the students.

Primary schools in Ganzi take two teaching modes: one is teaching every subject except Chinese in Tibetan and using Tibetan textbooks, and the other one is teaching every subject except Tibetan in Chinese and using state-compiled textbooks. So in the three Complete Primary Schools some students study in the first teaching mode classes, and some study in the second teaching mode classes. Students of the first mode are all Tibetans who are adept in Tibetan; on the other hand, students of the second mode which include both Han and Tibetan students are good at Chinese. What's more, in recent years some classes of excellent students are receiving the distant education from other parts of Sichuan Province like Chengdu and Longquan. Students have benefited a lot from the distant education and made more progress than before.

\subsubsection{The English Education in Primary Schools of Ganzi}

Primary schools of Ganzi County offer English course from the $3^{\text {rd }}$ grade, but except three primary schools in the county and one private school, primary schools in villages don't offer English course. There are totally 12 primary school English teachers in Ganzi County, which only accounts for $3.9 \%$ of the 310 primary school teachers. The survey shows that though the students only have English class twice a week, their motivation of learning English is very high and some of them even like to greet in English. English education in primary schools of Ganzi still faces numerous challenges and many problems which have to be analyzed in order to find proper solutions.

\subsubsection{Ganzi Primary School Students' Characteristics in Learning English}

Above 93\% students in primary schools of Ganzi are Tibetan, and many of them are from farming and animal husbandry families. Though primary schools are now tuition-free, the low family income has made the living condition of many students not too good. Some students in the three Complete Primary Schools come from places which are far away from the central town, so they have to stay in schools for a semester around. 
Table 1. Number of the parents who can speak English

\begin{tabular}{lll}
\hline & parents can speak English & parents can't speak English \\
\cline { 2 - 3 } 3rd grade & 10 & 40 \\
4th grade & 5 & 42 \\
5 th grade & 7 & 45 \\
\hline
\end{tabular}

From the survey of the students from $3^{\text {rd }}$ grade to $5^{\text {th }}$ grade in the No. 3 Complete Primary School, most parents can't help their children in English because of their lack of English knowledge, and some parents even haven't received any education. Most Tibetan students have to learn English by themselves out of class. What's more, the students' access to learning English is limited. They don't have many ways to learn English, like attending English course clubs and inviting English tutors.

Among Tibetan people, many parents used to let their children to go to mountains to collect Caterpillar Fungus (Dōng chóng xià căo) and Matsutake (Song rong) to make money. However, in these years more and more parents have realized the importance of the education, because a saying now has deeply rooted in many parents' hearts that the best Caterpillar Fungus and Matsutake are not in the highest mountains but in the classes. The education in the villages is not very good, so many parents have sent their children to the three Complete Primary Schools, especially the No. 3 Complete Primary School, which makes the number of the students in each class is above 50. The students have to learn English in a big class, and not every one of them can be noticed by the teachers, which influences the students' foundation of English from the beginning.

Although the students have met a lot of problems in learning English, they are still interested in English and have their own opinions on receiving English education.

Table 2. Tibetan students' interest on English

\begin{tabular}{llll}
\hline & very interested & interested & not interested \\
\cline { 2 - 3 } 3rd grade & 26 & 24 & 0 \\
4th grade & 25 & 20 & 2 \\
5th grade & 30 & 19 & 3 \\
\hline
\end{tabular}

The Tibetan students in primary schools think English is interesting and they are willing to communicate with their teachers. The survey shows that $65 \%$ students say that they have difficulty in English listening and they can't understand what the teacher says sometimes. Listening let them feel learning English is difficult and sometimes feel anxious, so they are keen on improving their listening. However, $75 \%$ of the students never listen to tapes or watch English movies after class, because of the limited condition for some students and improper instructions. Just as Wang Qiang mentioned 'One major reason for students' poor listening skill is that listening is often neglected in language teaching due to lack of teaching materials, both with print materials and audio or video tapes." (Wang, 2005: 136)

Many Tibetan students surveyed also give their expectation to English class and their teachers. Some students hope that English class can be more interesting than before. Most students are eager to improve their listening skill, and some students even think the teachers should be stricter with the students. The students' willingness of improving their English can reflect that they've realized the importance of learning English.

All in all, the Tibetan primary students are interested in English, and they are willing to communicate with others in English and hope to have a good foundation of English. However, many of their parents can't help them with English, and their living condition and improper teaching instructions have limited their development in listening.

\subsubsection{Ganzi Primary School Teachers' Characteristics in Teaching English}

99\% English teachers in primary schools of Ganzi are Hans who are from other places of Sichuan Province. Many of them come to Ganzi for the first time and know little about Tibetan culture and language, which makes their teaching sometimes have no relation to the students' real daily life. 
Table 3. Teachers' degrees

\begin{tabular}{lll}
\hline postgraduate & undergraduate & junior college graduate \\
\hline 0 & 2 & 10 \\
\hline
\end{tabular}

From Table 3, the teachers' degrees in primary schools of Ganzi are not high, and haven't reached the standard degree. From the survey, 2 of the 12 teachers are even not the full-time teachers who are not English majors but act as English teachers. This phenomenon reflects that Tibetan areas like Ganzi County really lack English teachers especially the teachers who are familiar with Tibetan and Tibetan culture.

Most English teachers in primary schools of Ganzi County haven't taught English for many years. The average teaching length of the English teachers is 3 years. Seven teachers have taught English for 1-3 years and only one teacher has taught English for 6 years. The teaching length sometime can reflect the teaching experience of one English teacher. Especially in Tibetan areas, more experience means more understanding of the teaching ways and the students' characteristics. However, the teaching length of the English teachers is really short, which has influenced the total teaching quality of English in Ganzi.

The work load of English teachers in primary schools is heavy. Although each class only has English courses twice a week, one grade has over five classes and a complete school only has 3-4 English teachers. Taking No. 3 Complete Primary School as an example, there are only three English teachers and they have to teach English in more than two grades. The teachers are busy with teaching in class, planning lessons and checking the students' work after class. So the teachers can't really plan a good lesson and arrange interesting games for the students according to their own learning characteristics. The teachers can't pay attention to the real acquirement of their students.

Meanwhile, according to the survey, the English teachers never discuss the students' English study with the students' parents, because firstly the English teachers don't attend the meetings held for parents. Secondly, though parents have realized the importance of education, they haven't paid much attention to children's English education. What's more, as shown in chart 1, many parents can't speak English and their awareness of the importance is still low, which makes teachers and parents can't cooperate and teachers lack the support from the students' parents.

To sum up, the English teachers in Ganzi know little about the students' real life and the local culture. Their heavy work has limited their contact with the students, the parents and the local culture, and this phenomenon is mainly due to the lack of English teachers in Ganzi County.

\subsubsection{The Characteristics of Other Influencing Factors of English Education in Ganzi}

First, as mother tongue, Tibetan plays an important role in most Tibetan students' lives. The medium of instructions for teachers in Ganzi is Chinese, because the teachers are not local Tibetans and can't speak Tibetan. However, many primary students especially those in lower grades like the $3^{\text {rd }}$ grade don't have good Chinese level, because most of them just begin to study Chinese from the $1^{\text {st }}$ grade. So it becomes difficult for them to learn English when Chinese is used as a medium. In the survey, many students hope that their teacher sometimes can use Tibetan to explain English and it would be easier for them to understand the teacher. Some students say they can easily memorize the meaning of some English words by the explanation in Tibetan. Using Chinese as the medium of instruction of English teaching in primary schools of Ganzi has influenced the students' English learning.

Second, many students can't really understand the background of textbooks. The information provided by English textbooks is not familiar to many Tibetan students, because their living environment is not all the same as described in the textbooks. They don't know much about the situation of many conversations in books. However, it is very important to go on a conversation in a proper situation. The books now used by the students have nothing to do with the Tibetan primary students' own lives and their familiar places, so textbooks also influence the Tibetan primary students' English learning to some degree. According to the survey, $90 \%$ students expect to see their familiar pictures, names and custom in the textbooks, which can make them feel more interested in English.

What's more, according to the interview to Mr. Luo, an officer in Education Bureau of Ganzi County, the English studying atmosphere in primary schools are not good due to the little attention to English both from the schools and parents. Although the students are eager to learn English, the lack of teachers, good arrangements of English teaching and few chances to use English has make some students feel a little disappointed. What's more, the 
equipment of English teaching is limited, and it is difficult for each class to have an electronic whiteboard. Teachers investigated hope schools can have a set of good English teaching equipment.

To sum up, many factors have influenced the English education in primary schools of Ganzi from the medium for instructions to the textbooks and the studying atmosphere, and English education in primary schools here is really facing many challenges and problems.

\subsubsection{The Necessity of English Education in Primary Schools of Ganzi}

With development of modern science and techniques, more and more people are getting closer with each other. People have to compete with each other to be the talents society need. For Chinese ethnic minorities, they have to know their ethnic minorities' culture and language and are also good at Chinese and foreign languages like English in order to be the talents. Offering English education in primary schools of Tibetan areas can help cultivate more skilled Tibetan talents. Those skilled Tibetan students can introduce their own culture to other countries, and foreigners can know more about China and her ethnic groups.

Above all, the English education in primary schools of Tibetan areas like Ganzi is facing many problems and challenges. Only by solving these problems can the whole education in Tibetan areas still go on and make progress. So it has been necessary to have English education in primary schools of Ganzi.

\section{The Solutions and Suggestions}

Through the analysis of the survey and interview about the situation of English education in primary schools of Ganzi, the English education has got stuck here and many problems are waiting for good solutions. According to the unique characteristics of the Tibetan students, the English teachers and other influencing factors, this thesis gives some solutions and creative suggestions in order to provide little help to the local English education in primary schools of Tibetan areas.

\subsection{The Cultivation of Tibetan English Teachers}

The survey shows that Ganzi only has 12 English teachers, and many problems have been caused by the lack of English teachers. Teachers' heavy work, teachers' little attention to the students, and little support of the parents are all caused by the lack of teachers. If the number of the English teacher can be increased, the load of the teachers can become lighter and the teacher can have more time and energy to care about the students' study and their own teaching plans and arrangement. What's more, the increasing number of teachers can make the whole team of English teachers in Ganzi stronger. A strong team can always come up with many wonderful ideas about English teaching, and they can make the whole county feel a good atmosphere of English. The students can become more interested in English under the construction of the teachers who are devoted to English education. English teachers also need to go out to study the good ways and methods in other primary schools of some developed areas, and according to the own characteristics of Tibetan areas come up with more available methods to the Tibetan students.

It is a good way to cultivate the English teachers who are Tibetans. Many Tibetan students feel anxious when many English words are explained by Chinese, because their Chinese hasn't been good enough to understand some sentences. If their teachers can sometimes use Tibetan for them to let them calm, they can learn English better. Using Tibetan as the medium of instruction can make the Tibetan students understand the meaning of some English words better. The Tibetan teachers always know the students' own culture and custom, and they have the same lifestyle and even same concepts about something. It can become easier for them to communicate with each other, and the English teachers who are Tibetans can set a good example to the Tibetan students that diligence can also lead Tibetan students to own good English ability. Tibetan areas need the trilingual education to make the students know more about the other culture and language and also cherish and protect Tibetan own culture and language. So cultivating English teachers who are Tibetans can make the English education in primary schools of Ganzi go on more smoothly.

\subsection{The Use of New Textbooks Closely Related to Tibetan Primary School Students'Lives}

The textbooks used by the students are the PEP edition, but some students are not very familiar with the background. Hu Zhuanglin says, "One thing we can say for certain is that language evolves within specific historical, social and cultural contexts" (Hu, 2010). It can be a good way to invite some experts who are good at English, Tibetan and their culture to compile a new textbook which is related to the real life of each Tibetan student. This textbook should really reflect the daily life of Tibetan students. It can illustrate the famous landscapes, custom and culture, for example, when the teacher teaches festivals, it can be a good way to introduce some famous Tibetan festivals like Tibetan New Year. The students can feel more interested about these topics which are closely related to them. What's more, these textbooks also need to aim to teach the 
students the right sense of responsibility. Compiling a textbook should comply with a standard of teaching requirement and pay attention to the right spelling of words and the applicability of the information. These textbooks should include a set of complementary materials like CD, cards, teachers' books, students' work books and exercise books. A textbook including the illustration of the students' daily life and all kinds of activities should be welcomed by many Tibetan students and teachers.

\subsection{The Standardization of English Course in Primary Schools of Ganzi County}

The primary schools of Ganzi offer English course for the students twice a week, but the students can't learn a lot in such limited time. In order to make the students have more chances to learn English and the teachers have more time to realize the teaching aims, it is necessary to increase the times of having English class in every week. According to the teaching requirements issued by the Ministry of Education of China, primary schools must offer English course at least four times a week. What's more, the teachers should arrange their new lessons within twenty minutes, because most children from seven to ten can only concentrate in a class about twenty minutes according to some psychological researches. So teachers should make full use of the first twenty minutes of a class and let the students have more chances to communicate in English and take part in activities.

\subsection{The Improvement of the Atmosphere of English Education in Ganzi}

Many teachers think that the parents of Tibetan students haven't paid much attention to English education. In order to improve the whole atmosphere of English education in Ganzi County, the Education Bureau of Ganzi County and schools should sometimes hold meeting for parents to let them know the importance of English. Teachers of different subjects can't take over the class for English. Schools should hold contests for teachers to practice their teaching ability and even invite some parents to attend these contests. What's more, schools can hold some speech contests or talent shows for students to practice English, and encourage the students to participate in different activities. Some programs of English can be added to the shows of Children's Day.

What's more, schools can let students have exams on English in the final examination of every semester. The English exam shouldn't be dull and complicated. The test can contain oral and written parts, and teachers can give interesting topics that they are fond of. The written part of the test should be fit for the students' ages and include both words and colorful illustrations.

\section{Conclusion}

The English education in Ganzi County is facing many challenges now. The local economy has influenced the development of the English education. Tibetan students in primary schools are eager to learn English and know more about other countries' culture. They want to have more chances to use English, but the limited English teachers can't take the students' real acquirement into consideration and they even can't finish their own lesson plans sometimes. Students want to improve their listening, but the teachers can't take right action to deal with such problems. Students want the English to be instructed by some Tibetan definitions, but the teachers here can not speak Tibetan at all. Students hope they can have a textbook which is really close to their lives. Teachers want the parents to cooperate with them, but some parents only know the importance of other subjects like Math and Chinese. Teachers want to find more available teaching methods, but their team is too small with only 12 persons. It is understandable that parents in rural areas send their children to the central town to get better education, but it is difficult for primary schools to accept too many students, which has already caused the huge number of students in each class. The English teachers can't find every student's problem when English is taught among too many students of a class. It is harmful for primary students to make some mistakes especially the mistakes of pronunciations and intonations at the beginning of their English learning, but the teachers don't have the energy to find these mistakes of the students at all.

Many problems exist in English education of primary schools in Ganzi, but as long as good solutions and suggestions can be put forward and more people and experts pay attention to the English education in Tibetan areas, the English education here are still promising. Tibetan students themselves from primary schools should make more effort than others to study English in order to keep up with the high pace of society.

As the thesis previously states, the researches on English education of primary schools in Tibetan areas are relatively necessary. This thesis has many shortcomings because of the limitation of resources and materials. There are only a few references written by foreign researchers. Hopefully, this thesis can let more people know the situation of English education in Tibetan primary schools and make them give more available suggestions.

\section{Acknowledgements}

This research is Financed by Research Center for Sichuan Provincial Education Development (Language Teaching and Its Policy, No. CJF011034) and LNU "A diachronic study on the localization of modern foreign 
language teaching methods in China" (No.C1421).

\section{References}

Hu, Z. L. (2010). Linguistics: A Course Book. Beijing: Peking University Publishing House.

Wang, Q. (2005). A Course in English Language Teaching. Beijing: High Education Press.

Deng, D. (2008). A Case Study on English Language Teaching, People’s Education Web Journal.

Du, H. (2008). A Study of Tibetan-Han-English-Structured Learning Features. Xichang University Journal

Zhou, M., \& Pu, Y. (2009). A Comparison Study on CAI Based on Titetan-Chinese Teaching Class.

Li, S. (2010). A comparison Study on Communication Motivation between Titetan-Han Students. Guizhou Minzu Outlook.

Wu, L. (2005). Trilingual Teaching Policy Interpretation. Guizhou Minzu Outlook.

\section{Copyrights}

Copyright for this article is retained by the author(s), with first publication rights granted to the journal.

This is an open-access article distributed under the terms and conditions of the Creative Commons Attribution license (http://creativecommons.org/licenses/by/3.0/). 